\title{
MULTI-STATE SYSTEM RELIABILITY
}




\section{SERIES IN QUALITY, RELIABILITY \& ENGINEERING STATISTICS}

Series Editors: M. Xie (National University of Singapore)

T. Bendell (Nottingham Polytechnic)

A. P. Basu (University of Missouri)

\section{Published}

Vol. 1: Software Reliability Modelling M. Xie

Vol. 2: Recent Advances in Reliability and Quality Engineering H. Pham

Vol. 3: Contributions to Hardware and Software Reliability P. K. Kapur, R. B. Garg \& S. Kumar

Vol. 4: Frontiers in Reliability

A. P. Basu, S. K. Basu \& S. Mukhopadhyay

Vol. 5: System and Bayesian Reliability

Y. Hayakawa, T. Irony \& M. Xie

Forthcoming title

Reliability Optimization \& Design of Fault Tolerant Systems

H. Pham

Mathematical and Statistical Methods in Reliability

B. Lindqvist \& K. Doksum 


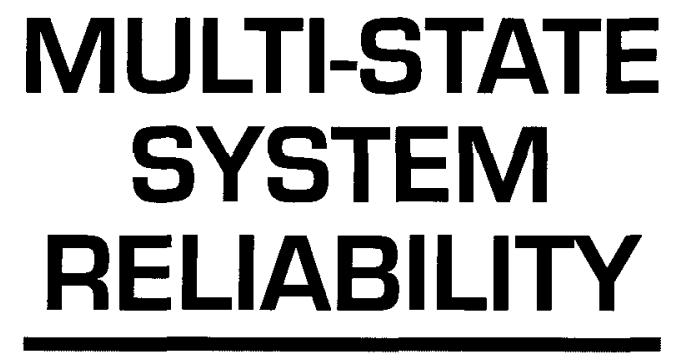

Assessment, Optimization and Applications

\section{Anatoly Lisnianski Gregory Levitin}

The Israel Electric Corporation Limited, Israel 


\section{Published by}

World Scientific Publishing Co. Pte. Ltd.

5 Toh Tuck Link, Singapore 596224

USA office: Suite 202, 1060 Main Street, River Edge, NJ 07661

UK office: 57 Shelton Street, Covent Garden, London WC2H 9HE

\section{British Library Cataloguing-in-Publication Data}

A catalogue record for this book is available from the British Library.

Series on Quality, Reliability and Engineering Statistics - Vol. 6

MULTI-STATE SYSTEM RELIABILITY

Assessment, Optimization and Applications

Copyright $(\mathcal{O} 2003$ by World Scientific Publishing Co. Pte. Ltd.

All rights reserved. This book, or parts thereof, may not be reproduced in any form or by any means, electronic or mechanical, including photocopying, recording or any information storage and retrieval system now known or to be invented, without written permission from the Publisher.

For photocopying of material in this volume, please pay a copying fee through the Copyright Clearance Center, Inc., 222 Rosewood Drive, Danvers, MA 01923, USA. In this case permission to photocopy is not required from the publisher.

ISBN 981-238-306-9 


\section{To our Parents}

Margarita and Lev

Lisnianski
Nella and Semion

Levitin 
This page is intentionally left blank

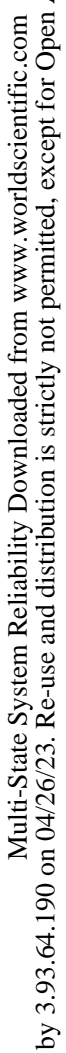




\section{Preface}

Most books on reliability theory are devoted to traditional binary reliability models allowing for only two possible states for a system and its components: perfect functionality and complete failure. However, many real-world systems are composed of multi-state components, which have different performance levels and several failure modes with various effects on the entire system performance. Such systems are called multi-state systems (MSS). The examples of MSS are power systems where the component performance is characterized by the generating capacity, computer systems where the component performance is characterized by the data processing speed etc. For the MSS the outage effect will be essentially different for units with different performance rates. Therefore, the reliability analysis of MSS is much more complex in comparison to binary-state systems. In real-world problems of MSS reliability analysis, the great number of system states that need to be evaluated makes it difficult to use traditional binary reliability techniques. From the middle of the 1970's and until now numerous research papers focusing on MSS reliability were published.

This book is the first that is devoted to MSS reliability analysis and optimization. It contains a brief historical overview of the field, presents basic concepts of MSS, defines MSS reliability measures and systematically describes the tools for the MSS reliability assessment and optimization. Basic methods for MSS reliability assessment, such as an extension of the Boolean methods, basic random process methods (both Markov and semi-Markov), and the universal generating function models are systematically studied. A Genetic Algorithm optimization technique and all of the details of its application are described. All the methods are illustrated by numerical examples. The book also contains numerous examples of applications of reliability assessment and optimization methods to real engineering problems.

The aim of this book is to give a comprehensive up-to-date presentation of MSS reliability theory based on modern advances in this field and to provide a theoretical summary along with examples of engineering applications to a variety of technical problems. From this point of view, the book bridges the gap between the theoretical advances and practical reliability engineering.

This book is suitable for different types of readers. It primarily addresses practicing reliability engineers and researchers with an interest in reliability and performance analysis. It can also be used as a textbook for senior undergraduate 
or graduate courses in several departments: nuclear engineering, industrial engineering, electrical and electronic engineering, computer science, and applied mathematics.

While selecting the topics to be included in this book we followed three basic principles:

1. The methods presented must be universal. This means that they can be applied to various types of systems and various problems. When considering methods for MSS reliability assessment we chose the three above mentioned basic approaches. As an optimization tool we present the universal genetic algorithm that can be applied to a wide range of problems and is extensively used in reliability optimizations by many researchers and practitioners.

2. The methods must be specifically MSS oriented. The general techniques (such as the Monte Carlo simulation) can be applied to MSS but are not designed specifically for analysis of these kinds of systems and, therefore, are not included in this book.

3. The applicability of the methods was an important criterion for their choice. Some of the scientific results are not discussed in this book, in spite of their theoretical importance, as they are difficult to apply.

Unfortunately some of the ideas and methods remained out of scope of this book due to its the restricted volume.

The book is divided into six chapters: basic concepts of MSS (chapter 1), tools for MSS reliability assessment and optimization (chapters $2,3,4,5$ ) and application problems (chapter 6).

The first chapter introduces the multi-state systems as the object of the study. It defines the generic model and describes the basic properties of the MSS. This chapter also introduces reliability indices used in MSS and presents examples of different MSS models.

The real technical systems that can be interpreted in the framework of the presented models are described (oil and gas transmission systems, transportation, communication and production systems, power generation, and supply systems).

Chapters 2, 3, and 4 present tools for MSS reliability assessment. They describe the general methods used for evaluating different MSS reliability indices and present illustrative examples.

Chapter 2 is devoted to an extension the Boolean methods for MSS reliability analysis. Such techniques as minimal path and cut vectors are considered as well as the fault tree analysis.

Chapter 3 is devoted to the random process methods. It presents Markov models for the calculation of MSS reliability measures and Markov reward models as a basic technique for the cost-reliability analysis of MSS. It also contains basic semi-Markov models for the MSS reliability analysis. It shows how the restrictions of the Markov models can be essentially relaxed by using the semi-Markov process technique. 
Chapter 4 is devoted to the Universal Generating Function (UGF) method. It presents an extension of the Reliability Block Diagram method to MSS and the UGF-based approach for reliability evaluation of different types of MSS. The method is extended to provide the importance and the sensitivity analysis of MSS. The chapter also shows how a combination of the Markov process technique with the UGF method reduces the computational burden when estimating MSS reliability indices.

Chapter 5 contains a general description of the reliability optimization problems and an overview of the optimization problems that arise in reliability engineering. It presents a universal optimization tool for their solution named the genetic algorithm.

Chapter 6 describes examples of various applications of the presented methods for solving problems of MSS reliability improvement and optimization. It contains examples of applying Markov and Markov reward models for decision making based on the comparative reliability analysis of different versions of redundancy allocation (the power station feeding pumps system is considered).

The chapter presents definitions and solutions of various application problems related to the structure and maintenance policy optimization for different types of MSS. It also considers a case when during the MSS lifetime the demand and reliability requirements can change.

An approach to solving some additional MSS reliability optimization problems such as the optimal test time allocation for MSS reliability growth testing and MSS survivability maximization are also presented.

Chapters 1-4 have exercises that can be used in the teaching process and can help in understanding the presented notions and the computation techniques.

In the concluding remarks we outline the major promising directions of further research in the MSS field.

We would like to express our sincere appreciation to Prof. Min Xie from the National University of Singapore, Editor-in-Chief of the World Scientific Series on Reliability, Quality and Engineering Statistics for providing us with the chance to include the book as one in the series and for his valuable comments that improved the book. We would like to thank our teacher and friend Prof. Igor Ushakov and our colleagues Dr. David Elmakis, Dr. Hanoch Ben Haim, Mr. Gideon Heller and Dr. David Laredo from The Israel Electric Corporation for their friendly support and discussions from which the book benefited.

We are also indebted to the many researchers who have developed the underlying concepts of this book. Although far too numerous to mention, we have tried to recognize their contributions through bibliographical references.

It was a pleasure working with the World Scientific editor Chelsea Chin.

Special thanks must also go to our wives Ella and Irina for their support. 
This page is intentionally left blank

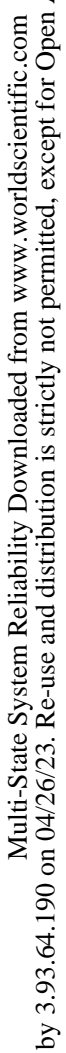




\section{Contents}

Preface v v

Introduction and brief historical overview 1

$\begin{array}{ll}\text { General notation and acronyms } & 13\end{array}$

Chapter 1. Basic concepts of Multi-State Systems 15

1.1. Multi-state systems: main definitions and properties 15

$\begin{array}{ll}\text { 1.1.1. Generic MSS model } & 16\end{array}$

$\begin{array}{ll}\text { 1.1.2. Main properties of MSS } & 21\end{array}$

$\begin{array}{ll}1.1 .2 .1 . \text { Relevancy of the system elements } & 21\end{array}$

$\begin{array}{ll}1.1 .2 .2 . \text { Coherency } & 22\end{array}$

1.1.2.3. Homogeneity 23

1.2. Multi-state system reliability and its measures 24

1.2.1. MSS acceptability function and reliability 24

1.2.2. Relevancy and coherency in MSS reliability context 25

$\begin{array}{ll}\text { 1.2.3. MSS reliability indices } & 26\end{array}$

1.3. Types of MSS

1.3.1. MSS with typical simple configurations 33

$\begin{array}{ll}\text { 1.3.1.1. Series structure } & 33\end{array}$

$\begin{array}{ll}\text { 1.3.1.2. Parallel structure } & 35\end{array}$

$\begin{array}{ll}\text { 1.3.1.3. Bridge structure } & 38\end{array}$

$\begin{array}{ll}\text { 1.3.2. Systems with two failure modes } & 40\end{array}$

$\begin{array}{ll}\text { 1.3.3. Weighted voting systems } & 40\end{array}$

1.3.4. Multi-state consecutively connected systems 42

1.3.5. Multi-state sliding window systems 44

$\begin{array}{ll}\text { 1.3.6. Multi-state networks } & 45\end{array}$

1.3.6.1. Multi-state edges models $\quad 47$

1.3.6.2. Multi-state vertices models $\quad 47$

1.3.6.3. Mixed multi-state models $\quad 48$

Exercises $\quad 48$

References $\quad 49$ 


\section{Chapter 2. Extension of Boolean methods for MSS reliability} analysis

2.1. Multi-valued structure function approach 51

2.1.1. Path and cut vectors 51

2.1.2. Multi-valued structure function $\quad 55$

2.1.3. Evaluating the system reliability indices 63

2.1.4. Reliability bounding 66

2.2. Multi-state block diagrams and fault trees 67

2.2.1. Structure function representation using binary variables $\quad 67$

2.2.2. MSS reliability block diagrams 68

2.2.3. MSS fault trees 72

2.2.4. Multi-valued logic trees and Boolean algebra with restrictions

2.2.4.1. Basic definitions of Boolean algebra with restrictions

2.2.4.2. Boolean reduction of multi-valued logic trees

2.2.4.3. Derivation of the complete base of prime implicants

Exercises

References

\section{Chapter 3. Basic random processes methods for MSS reliability} assessment

3.1. General concepts $\quad 89$

3.2. Markov models $\quad 92$

3.2.1. Main definitions and properties 92

3.2.2. Markov models for evaluating reliability of multi-state elements

3.2.2.1. Non-repairable multi-state elements $\quad 95$

3.2.2.2. Repairable multi-state elements 102

3.2.2.3. Markov models for the multi-state element with variable demand

3.2.3. Markov models for evaluating the reliability of the multistate system

3.3. Markov reward models

3.3.1. Basic definitions and model description 128

3.3.2. Computation of MSS reliability measures $\quad 132$

3.3.2.1. Mean number of failures 
3.4. Semi-Markov models 137

3.4.1. Definition of Semi-Markov process 137

3.4.2. Evaluation of MSS reliability indices based on semi-

Markov models $\quad 142$

Exercises

150

References 151

Chapter 4. Universal Generating Function (UGF) models

4.1. Mathematical fundamentals 155

4.1.1. Definition of universal generating function $\quad 155$

4.1.2. Evaluating MSS reliability indices based on the UGF $\quad 160$

4.1.3. Properties of composition operators 163

4.2. Reliability block diagram method 165

4.2.1. UGF of subsystems containing series elements 166

4.2.2. UGF of subsystems containing parallel elements $\quad 168$

4.2.3. UGF of series-parallel systems 171

$\begin{array}{ll}\text { 4.2.4. Bridge structure } & 177\end{array}$

4.2.4.1. Flow transmission MSS 177

$\begin{array}{ll}\text { 4.2.4.2. Task processing MSS } & 178\end{array}$

4.2.4.3. Simplification technique $\quad 180$

4.2.5. Combined UGF and random process technique 182

4.3. Reliability assessment for different types of MSS 187

$\begin{array}{ll}\text { 4.3.1. Systems with Two Failure Modes } & 187\end{array}$

4.3.1.1. Flow transmission MSS (with flow dispersion) $\quad 189$

4.3.1.2. Task processing MSS 190

4.3.2. Weighted voting systems and classifiers 194

4.3.2.1. Evaluating reliability of weighted voting systems 194

4.3.2.2. Simplification technique 198

4.3.2.3. Evaluating reliability of weighted voting classifiers 201

4.3.2.4. Simplification technique 207

4.3.3. Linear multi-state consecutively-connected systems 210

4.3.3.1. Connectivity model 210

4.3.3.2. Model with retransmission delays 215

4.3.3.3. Simplification technique 218

4.3.3.4. Model with variable retransmission delays 222

4.3.4. Sliding window systems $\quad 222$

4.3.4.1. Evaluating availability of sliding window systems $\quad 222$

4.3.4.2. Simplification technique 226

4.3.5. Multi-state networks 228

4.3.5.1. MAN connectivity model 229 
4.3.5.2. MAN with constant transmission characteristics of arcs

4.3.6. Incorporating common cause failures into UGF models

4.4. UGF based method of MSS importance and sensitivity analysis 246

Exercises

References

Chapter 5. MSS reliability optimization

5.1. Optimization problems in reliability

5.2. Genetic algorithm as a universal optimization technique

5.3. Adaptation of genetic algorithm to specific optimization problems

5.3.1. Representation of solutions in GA

5.3.1.1. Parameter determination problems

5.3.1.2. Partition and allocation problems

5.3.1.3. Mixed partition and parameter determination problems

5.3.1.4. Sequencing problems

5.3.2. Determination of solution fitness

5.3.3. Crossover and mutation procedures

5.3.4. Determination of GA parameters

References

Chapter 6. Application Problems

6.1. Practical decision making based on cost-type criterion

6.2. MSS structure optimization

6.2.1. Minimal cost MSS structure subject to availability constraints

6.2.1.1. Problem formulation

6.2.1.2. Implementing the GA

6.2.2. Single stage expansion of MSS

6.2.3. Single stage replacement (modernization) of MSS elements

6.2.3.1. Problem formulation

6.2.3.2. Implementing the GA

6.2.4. Structure optimization of series-parallel MSS with two failure modes

6.2.4.1. Problem formulation

6.2.4.2. Implementing the GA 
6.2.5. Optimization of MSS parameters 305

6.2.5.1. Implementing the GA 305

6.2.6. Optimal arrangement (sequencing) of MSS elements $\quad 307$

6.2.6.1. Implementing the GA 307

6.2.7. Optimal allocation of MSS elements 309

6.2.7.1. Problem formulation and GA implementation 311

6.3. MSS maintenance optimization $\quad 312$

$\begin{array}{ll}\text { 6.3.1. Optimal cyclic replacement policy } & 312\end{array}$

6.3.1.1. Problem formulation $\quad 314$

6.3.1.2. Implementing the GA 315

6.3.2. Joint redundancy and maintenance optimization $\quad 319$

6.3.1.1. Problem formulation $\quad 319$

6.3.2.2. Implementing the GA 321

6.3.3. Optimal imperfect maintenance 324

6.3.3.1. Element age reduction model $\quad 325$

6.3.3.2. Problem formulation 326

6.3.3.3. Implementing the GA 327

6.4. Optimal multistage MSS expansion scheduling 331

6.4.1. Problem formulation $\quad 332$

6.4.2. Implementing the GA 333

6.5. Optimization of MSS reliability growth testing 336

6.5.1. Problem formulation 337

6.5.2. Implementing the GA 338

6.6. MSS survivability optimization $\quad 342$

6.6.1. Optimal separation of MSS elements 342

6.6.1.1. Problem formulation $\quad 343$

6.6.1.2. Implementing the GA 344

6.6.2. Optimal allocation of MSS elements subject to

6.6.2.1. Problem formulation and GA implementation $\quad 349$

References 351

Concluding remarks (further research) 353

$\begin{array}{ll}\text { Index } & 357\end{array}$ 